\title{
1 \\ The Role of Pollution Prevention in Stormwater Management
}

Robert Pitt and Melinda Lalor

Around the nation, there is growing interest in the development and use of environmentally sensitive construction materials as a low-cost component to stormwater management. It is thought that the more appropriate selection of materials that are exposed to the environment should result in significant reductions of many toxicants in stormwater. Unfortunately, there is little data for specific alternative building materials, although much information exists targeting selected sources, especially the role of roof runoff as a significant source of zinc and other metals.

Past studies have identified urban runoff as a major contributor to the degradation of many urban streams and rivers (such as Field and Turkeltaub 1981; Pitt and Bozeman, 1982; Pitt and Bissonnette, 1984; Pitt, 1995). Previous studies also found organic and metallic toxicants in urban storm-induced discharges that can contribute to receiving water degradation (such as EPA, 1983; Hoffman et al., 1984; Fram et al., 1987). Studies conducted by Pitt et al. (1995 and 2000) investigated toxic contributions to urban wet weather flow from sources such as roofs, parking areas, storage areas, streets, loading docks, vehicle service areas, and landscaped areas. Roof, vehicle service area and parking lot runoff samples were found to have the greatest organic toxicant detection frequencies and the highest levels of detected metals. Research is currently underway at the University of Alabama (UAB) to develop effective procedures for treating runoff from vehicle service areas and parking lots at its source (Clark and Pitt 1999; Pitt et al., 2000). These areas are particularly subject to spills and leaks of automotive products and exhaust emissions from

Pitt, R.E. and M. Lalor. 2001. "The Role of Pollution Prevention in Stormwater Management." Journal of Water Management Modeling R207-01. doi: 10.14796/JWMM.R207-01.

(C) CHI 2001 www.chijournal.org ISSN: 2292-6062 (Formerly in Models and applications to Urban Water Systems. ISBN: 0-9683681-4-X) 
frequently starting vehicles. These areas are usually isolated enough to make source area runoff treatment feasible. However, relative pollutant contributions from various roofing, wooden and paving materials themselves are also a concern which has not been adequately addressed. Due to the common use of these surfaces in our urban environments, reduction of emissions at the source is desirable, and material substitution would seem a good place to start.

\subsection{Sources of Urban Runoff Pollutants and Source Reduction Options}

It has been known for many years that most stormwater toxicants and much of the conventional pollutants are associated with automobile use and maintenance activities and that these pollutants are strongly associated with the particulates suspended in the stormwater (the non-filterable components, or suspended solids). It has been difficult to reduce or modify automobile use to reduce the use of these compounds, with the notable exception of the phasing out of leaded gasoline. Current activities, concentrated in the San Francisco area, are trying to encourage brake pad manufacturers to reduce the use of copper. The effectiveness of most stormwater control practices is therefore dependent on their ability to remove these particles from the water, or possibly from intermediate accumulating locations (such as streets or other surfaces) and not through source reduction. The removal of these particles from stormwater is dependent on various characteristics of these particles, especially their size and settling rates. Some source area controls (most notably street cleaning) affect the particles before they are washed-off and transported by the runoff, while others remove the particles from the flowing water.

Table 1.1 shows that most of the organic compounds found in stormwater are associated with various human-related activities, especially automobile and pesticide use, or are associated with plastics (Verschueren, 1983). Heavy metals found in stormwater also mostly originate from automobile use activities, including gasoline combustion, brake lining, fluids (brake fluid, transmission oil, anti-freeze, grease, etc.), undercoatings, and tire wear (Koeppe, 1977; Rubin, 1976; Shaheen, 1975; Solomon and Natusch, 1977; Wilbur and Hunter, 1980). Auto repair, pavement wear, and deicing compound use also contribute heavy metals to stormwater (Field et al. 1973, and Shaheen 1975). Shaheen (1975) found that eroding area soils are the major source of the particulates in stormwater. The eroding area soil particles, and the particles associated with road surface wear, become contaminated with exhaust emissions and runoff containing the polluting compounds. Most of these compounds become tightly bound to these particles and are then transported 
through the urban area and drainage system (or removed) with the particulates. Stormwater concentrations of zinc, fluoranthene, 1,3-dichlorobenzene, and pyrene are unique in that substantial fractions of these compounds remain in the water and are less associated with the particulates.

Table 1.1 Uses and sources for organic compounds found in stormwater (source: Verschueren 1983).

\begin{tabular}{ll} 
Compound & Example Use/Source \\
\hline $\begin{array}{l}\text { Phenol } \\
\text { N-Nitroso-di-n-propylamine } \\
\text { Hexachloroethane }\end{array}$ & $\begin{array}{l}\text { gasoline, exhaust } \\
\text { contaminant of herbicide Treflan } \\
\text { plasticizer in cellulose esters, minor use in rubber and } \\
\text { insecticide } \\
\text { solvent, rubber, lubricants } \\
\text { Nitrobenzene }\end{array}$ \\
$\begin{array}{l}\text { asphalt, fuel, plastics, pesticides } \\
\text { Hexachlorobutadiene }\end{array}$ & $\begin{array}{l}\text { rubber and polymer solvent, transformer and hydraulic oil } \\
\text { germicide; preservative for glues, gums, inks, textile, and }\end{array}$ \\
l-Chloro-3-methylphenol & $\begin{array}{l}\text { insecticide, algaecide, herbicide, \& fungicide mfg., wood } \\
\text { preservative }\end{array}$ \\
Pentachlorophenol & gasoline, motor and lubricating oil, wood preservative \\
Fluoranthene & $\begin{array}{l}\text { gasoline, asphalt, wood preservative, motor oil } \\
\text { general use of plastics }\end{array}$ \\
Pyrene & Di-n-octylphthalate
\end{tabular}

All areas are affected by atmospheric deposition, while other sources of pollutants are specific to the activities conducted on the areas. As examples, the ground surfaces of unpaved equipment or material storage areas can become contaminated by spills and debris, while undeveloped land remaining relatively unspoiled by activities can still contribute runoff solids, organics, and nutrients, if eroded. Atmospheric deposition, deposition from activities on paved surfaces, and the erosion of material from upland unconnected areas are the major sources of pollutants in urban areas.

The important sources of these pollutants are related to various uses and processes. Automobile related potential sources usually affect road dust and dirt quality more importantly than other particulate components of the runoff system. The road dust and dirt quality is affected by vehicle fluid drips and spills (gasoline, oils, etc.) and vehicle exhaust, along with various vehicle wear, local soil erosion, and pavement wear products. Urban landscaping practices potentially affecting urban runoff include vegetation litter, fertilizer and pesticide. Miscellaneous sources of urban runoff pollutants include firework debris, wildlife and domestic pet wastes and possibly industrial and sanitary wastewaters. Wet and dry atmospheric contributions both affect runoff quality. Pesticide use in an urban area can contribute significant quantities of various toxic materials to urban runoff. Many manufacturing and industrial activities, including the combustion of fuels, also affects urban runoff quality. 
Natural weathering and erosion products of rocks contribute most of the hardness and iron in urban runoff pollutants. Road dust and associated automobile activities (gasoline exhaust products) historically contributed most of the lead in urban runoff. However, the decrease of lead in gasoline has resulted in current stormwater lead concentrations being about $1 / 10$ of the levels found in stormwater in the early 1970s (Bannerman et al., 1993). In certain situations, paint chipping can also be a major source of lead in urban areas. Road dust contaminated by tire wear products, and zinc plated metal erosion, contribute most of the zinc to urban runoff. Urban landscaping activities can be a major source of cadmium (Phillips and Russo, 1978). Electroplating and ore processing activities can also contribute chromium and cadmium.

Many pollutant sources are specific to a particular area and on-going activities. For example, iron oxides are associated with welding operations and strontium, used in the production of flares and fireworks, would probably be found on the streets in greater quantities around holidays, or at the scenes of traffic accidents. The relative contribution of each of these potential urban runoff sources, is, therefore, highly variable, depending upon specific site conditions and seasons.

\subsubsection{Other Pollutant Contributions to the Storm Drainage System}

The detection of pentachlorophenols in stormwater indicates leaching from treated wood. Frequent detections of polycyclic aromatic hydrocarbons (PAHs) during the U.S. Environmental Protection Agency's Nationwide Urban Runoff Program (EPA 1983) may possibly indicate leaching from creosote treated wood, in addition to fossil fuel combustion sources. High concentrations of copper, and some chromium and arsenic observations also indicate the potential of leaching from "CCA" (copper, chromium, and arsenic) treated wood. The significance of these leachate products in the receiving waters is currently unknown, but alternatives to these preservatives should be considered. Many cities use aluminum and concrete utility poles instead of treated wood poles. This is especially important considering that utility poles are usually located very close to the drainage system ensuring an efficient delivery of leachate products. Many homes currently use wood stains containing pentachlorophenol and other wood preservatives. Similarly, the construction of retaining walls, wood decks and playground equipment with treated wood is common. Some preservatives (especially creosote) cause direct skin irritation, besides contributing to potential problems in receiving waters. Many of these wood products are at least located some distance from the storm drainage system, allowing some improvement to surface water quality by infiltration through pervious surfaces. 


\subsubsection{Sources of Stormwater Toxicants}

Tables 1.2 and 1.3 summarize toxicant concentrations and likely sources or locations having some of the highest concentrations found by Pitt et al. (1995). The detection frequencies for the heavy metals are all close to $100 \%$ for all source areas, while the detection frequencies for the organics shown ranged from about $10-25 \%$. Vehicle service areas had the greatest abundance of observed organics, with landscaped areas having many of the observed organics.

Table 1.2 Heavy metal source area observations (Pitt et al. 1995).

\begin{tabular}{lclll}
\hline Toxicant & $\begin{array}{l}\text { Highest median } \\
\text { conc. }(\mu \mathrm{g} / \mathrm{L})\end{array}$ & Source Area & $\begin{array}{l}\text { Highest conc. } \\
(\mu \mathrm{g} / \mathrm{L})\end{array}$ & Source Area \\
\hline Cadmium & 8 & $\begin{array}{l}\text { vehicle service } \\
\text { area runoff } \\
\text { landscaped area } \\
\text { runoff } \\
\text { urban receiving } \\
\text { water }\end{array}$ & 220 & street runoff \\
Chromium & 100 & 1250 & roof runoff \\
Copper & 160 & 330 & street runoff \\
Lead & 75 & $\begin{array}{l}\text { parking area } \\
\text { runoff } \\
\text { roof runoff }\end{array}$ & 130 & $\begin{array}{l}\text { storage area } \\
\text { landscaped area } \\
\text { runoff } \\
\text { roof runoff }\end{array}$ \\
\hline Nickel & 40 & 1580 &
\end{tabular}

Table 1.3 Toxic organic source area observations (Pitt et al. 1995).

\begin{tabular}{lcll}
\hline Toxicant & $\begin{array}{l}\text { Maximum } \\
(\mu \mathrm{g} / \mathrm{L})\end{array}$ & $\begin{array}{l}\text { Detection } \\
\text { Frequency } \\
(\%)\end{array}$ & Significant Sources \\
\hline Benzo (a) anthracene & 60 & 12 & gasoline, wood preservative \\
Benzo (b) fluoranthene & 226 & 17 & gasoline, motor oils \\
Benzo (k) fluoranthene & 221 & 17 & gasoline, bitumen, oils \\
Benzo (a) pyrene & 300 & 17 & asphalt, gasoline, oils \\
Fluoranthene & 128 & 23 & oils, gasoline, wood preservative \\
Naphthalene & 296 & 13 & coal tar, gasoline, insecticides \\
Phenanthrene & 69 & 10 & oils, gasoline, coal tar \\
Pyrene & 102 & 19 & oils, gasoline, bitumen, coal tar, \\
& & & wood preservative \\
Chlordane & 2.2 & 13 & insecticide \\
Butyl benzyl phthalate & 128 & 12 & plasticizer \\
Bis (2-chloroethyl) ether & 204 & 14 & fumigant, solvents, insecticides, \\
& & & paints, lacquers, varnishes \\
Bis (2-chloroisopropyl) ether & 217 & 14 & pesticides \\
pesticides
\end{tabular}




\subsubsection{Potential Sources}

A drainage system captures runoff and pollutants from many source areas, all with individual characteristics influencing the quantity of runoff and pollutant load. Impervious source areas may contribute most of the runoff during small storm events (e.g. paved parking lots, streets, driveways, roofs, sidewalks, etc.). Pervious source areas can have higher material washoff potentials and become important contributors for larger storm events when their infiltration rate capacity is exceeded (e.g. gardens, bare ground, unpaved parking areas, construction sites, undeveloped areas, etc.). Many other factors also affect the pollutant contributions from source areas, including: surface roughness, vegetative cover, gradient, and hydraulic connections to a drainage system; rainfall intensity, duration, and antecedent dry period; and pollutant availability due to direct contamination from local activities, cleaning frequency/efficiency, and natural and regional sources of pollutants. The relative importance of the different source areas is therefore a function of the area characteristics, pollutant washoff potential, and the rainfall characteristics (Pitt 1987).

Important sources of toxicants are often related to the land use (e.g. high traffic capacity roads, industrial processes, and storage area) that are unique to specific land uses activities. Automobile related sources affect the quality and quantity of road dust particles through gasoline and oil drips/spills; deposition of exhaust products; and wear of tire, brake, and pavement materials (Shaheen 1975). Urban landscaping practices potentially produce vegetation cuttings and fertilizer and pesticide washoff. Miscellaneous sources include holiday firework debris, wildlife and domestic pet wastes, and possible sanitary wastewater infiltration. In addition, resuspension and deposition of pollutants/particles via the atmosphere can increase or decrease the contribution potential of a source area (Pitt and Bozeman 1982; Bannerman et al. 1993).

Numerous source area samples were collected by Pitt et al. (1995). Roof runoff, parking area and vehicle service area samples had the greatest detection frequencies for the organic toxicants. Vehicle service areas and urban creeks had several of the observed maximum organic compound concentrations. Most of the organics were associated with the non-filtered sample portions, indicating an association with the particulate sample fractions. The compound 1,3dichlorobenzene was an exception, having a significant dissolved fraction.

In contrast to the organics, the heavy metals analyzed were detected in almost all samples, including the filtered sample portions. The non-filtered samples generally had much higher concentrations, with the exception of zinc which was mostly associated with the dissolved sample portion (i.e. not associated with the suspended solids, SS). Roof runoff generally had the highest concentrations of zinc, probably from galvanized roof drainage 
components, as previously reported by Bannerman et al. (1983), and others. Parking and storage areas had the highest nickel concentrations, while vehicle service areas and street runoff had the highest concentrations of cadmium and lead. Urban creek samples had the highest copper concentrations, which were probably due to illicit industrial connections or othernon-stormwater discharges.

Table 1.4 shows the relative toxicities of the collected stormwaters. A wide range of toxicities were found. About $9 \%$ of the non-filtered samples were considered highly toxic using the Microtox ${ }^{\mathrm{TM}}$ toxicity screening procedure. About $32 \%$ of the samples were moderately toxic and about $59 \%$ were considered non-toxic. The greatest percentage of samples considered the most toxic were from industrial storage and parking areas. Landscaped areas also had a high incidence of highly toxic samples (presumably due to landscaping chemicals), and roof runoff had some highly toxic samples (presumably due to high zinc concentrations). The chemical analyses also generally found much higher toxicant concentrations in the non-filtered sample portions, compared to the filtered sample portions.

Table 1.4 Relative toxicity of samples using Microtox ${ }^{\mathrm{TM}}$ (non-filtered) (Pitt et al. 1995).

\begin{tabular}{lcccc} 
Local Source Areas & $\begin{array}{c}\text { Highly } \\
\text { Toxic } \\
(\%)\end{array}$ & $\begin{array}{c}\text { Moderately } \\
\text { Toxic } \\
(\%)\end{array}$ & $\begin{array}{c}\text { Not } \\
\text { Toxic } \\
(\%)\end{array}$ & $\begin{array}{c}\text { Number of } \\
\text { Samples }\end{array}$ \\
\hline Roofs & 8 & 58 & 33 & 12 \\
Parking Areas & 19 & 31 & 50 & 16 \\
Storage Areas & 25 & 50 & 25 & 8 \\
Streets & 0 & 67 & 33 & 6 \\
Loading Docks & 0 & 67 & 33 & 3 \\
Vehicle Service Areas & 0 & 40 & 60 & 5 \\
Landscaped Areas & 17 & 17 & 66 & 6 \\
Urban Creeks & 0 & 11 & 89 & 19 \\
Detention Ponds & 8 & 8 & 84 & 12 \\
All Areas & $9 \%$ & $32 \%$ & $59 \%$ & 87 \\
\hline
\end{tabular}

Microbics suggested toxicity definitions for 35 minute exposures:

Highly Toxic - light decrease $>60 \%$

Moderately Toxic - light decrease $<60 \% \&>20 \%$

Not Toxic - light decrease $<20 \%$

\subsection{The Use of SLAMM to Identify and Quantify Source Area Contributions}

SLAMM, the Source Loading and Management Model, was originally developed to better understand the relationships between sources of urban runoff pollutants and runoff quality (Pitt and Voorhees, 1996). It has been continually 
expanded since the late 1970s and now includes a wide variety of source area and outfall control practices (infiltration practices, wet detention ponds, porous pavement, street cleaning, catchbasin cleaning, and grass swales). SLAMM is strongly based on actual field observations, with minimal reliance on purely theoretical processes that have not been adequately documented or confirmed in the field. SLAMM is mostly used as a planning tool, to better understand sources of urban runoff pollutants and their control.

Special emphasis has been placed on small storm hydrology and particulate washoff in SLAMM. Many currently-available urban runoff models have their roots in drainage design where the emphasis is with very large and rare rains. In contrast, stormwater quality problems are mostly associated with common and relatively small rains. The assumptions and simplifications that are legitimately used with drainage design models are not appropriate for water quality models. SLAMM therefore incorporates unique process descriptions to more accurately compute the sources of runoff pollutants and flows for the storms of most interest in stormwater quality analyses. However, SLAMM can be effectively used in conjunction with drainage design models to incorporate the mutual benefits of water quality controls on drainage design. Many SLAMM users have also incorporated the use of the model with a GIS.

The development of SLAMM began in the mid 1970s, primarily as a data reduction tool for use in early street cleaning and pollutant source identification projects sponsored by the EPA's Storm and Combined Sewer Pollution Control Program, and has been greatly expanded over the past $20 \mathrm{y}$ or more. SLAMM can now be effectively used as a tool to enable watershed planners to obtain a better understanding sources of pollutants and of the effectiveness of different control practice programs. Various attributes of SLAMM have been published in Volumes 6 through 8 of the proceedings of the stormwater user's conference given annually in Toronto (Pitt, 1997; Pitt, 1998; Pitt and Lantrip, 1999).

One of the first problems in evaluating an urban area for stormwater controls is the need to understand where the pollutants of concern are originating under different rain conditions. Figure 1.1 is an example for a typical medium density residential area showing the percentage of stormwater volume originating from different major source areas, as a function of rain depth. For storms of up to about 0.1 inch $(2.54 \mathrm{~mm})$ in depth, street surfaces contribute about one-half to the total runoff to the outfall. This contribution decreased to about $20 \%$ for storms greater than about 0.25 inch $(6.35 \mathrm{~mm})$ in depth. This decrease in the significance of streets as a source of stormwater is associated with an increase of water contributions from landscaped areas (which make up more than $75 \%$ of the area and have clayey soils). Similarly, the significance of runoff from driveways and roofs also starts off relatively high and then decreases with increasing storm depth. Obviously, this is just an example and 
the source contributions would vary greatly for different land uses/development conditions, rainfall patterns, and the use of different source area controls.

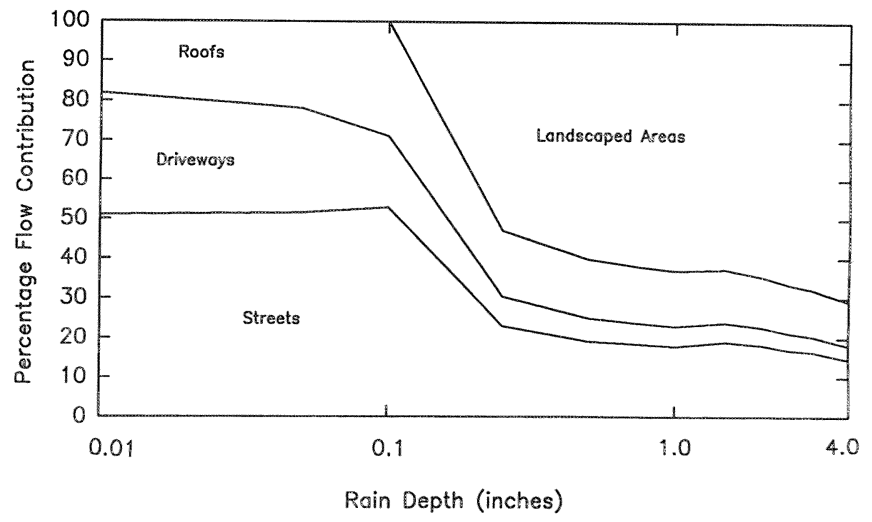

Figure 1.1 Flow sources for example medium density residential area having clayey soils (Pitt and Voorhees 1996).

SLAMM can be used to quantify the effects that different urban surfaces have on stormwater quality. In the above example, the roofs contributed about $10-20 \%$ of the runoff water (typical for most residential areas), but additional analyses indicate that roof runoff contributes the majority of the zinc in stormwater. The importance of pavements is also illustrated when using SLAMM for most areas, showing a potential for pollutant discharge modifications if alternative materials are used. The following section is a review of stormwater contributions from different roofing and paving materials. It is clear that pollution prevention opportunities are available with the careful selection of materials used in construction.

\subsection{Potential Materials and Alternatives Available for Stormwater Pollution Prevention}

Based on the results of many source area monitoring activities, candidate urban surfaces having potential for pollution reductions through the appropriate selection of alternative materials include roofing and paving materials. Building siding is also of concern as it is also exposed to rain and may cause some of the same problems currently found for roofing. The use of treated wood is also a concern. The following list shows typical components used for roofs and pavement surfaces: 


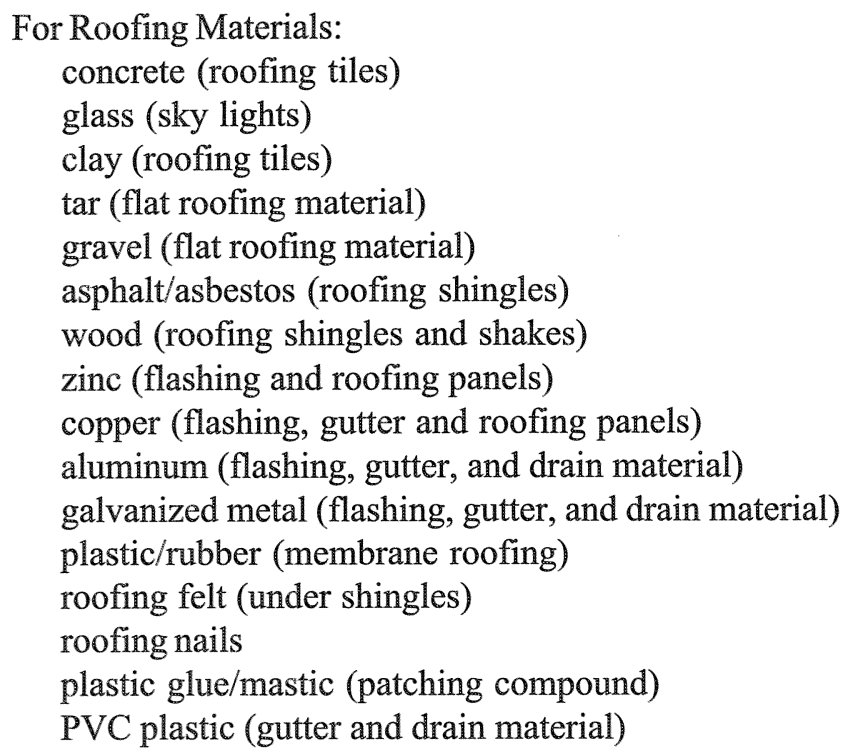

For Paved Surfaces:

Asphaltic cement flexible pavement

Portland cement rigid pavement

\subsubsection{Roofing and Paving Materials}

Boller (1997) identified heavy metals such as cadmium, copper, lead and zinc as the critical metals in domestic wastewaters and, based on his flow studies, concluded that runoff from roofs and streets contribute $50-80 \%$ of these metals to the total mass flow in Swiss combined sewer systems. Roof runoff samples, from tile, polyester, and flat gravel roofs, were analyzed and metal concentrations were found to vary with roof type. First flush analyses showed polyester roofs contributing highest concentrations of copper $(6,817 \mu \mathrm{g} / \mathrm{L})$, zinc $(2,076$ $\mu \mathrm{g} / \mathrm{L})$, cadmium $(3.1 \mu \mathrm{g} / \mathrm{L})$ and lead $(510 \mu \mathrm{g} / \mathrm{L})$. Concentrations in runoff from tile roofs were copper $(1,905 \mu \mathrm{g} / \mathrm{L})$, zinc $(360 \mu \mathrm{g} / \mathrm{L})$, cadmium $(2.1 \mu \mathrm{g} / \mathrm{L})$ and lead $(172 \mu \mathrm{g} / \mathrm{L})$. Runoff from flat gravel roofs also contributed copper $(140 \mu \mathrm{g} /$ $\mathrm{L})$, zinc $(36 \mu \mathrm{g} / \mathrm{L})$, cadmium $(0.2 \mu \mathrm{g} / \mathrm{L})$ and lead $(22 \mu \mathrm{g} / \mathrm{L})$. Runoff from roofs was found to contain not only heavy metals, but polycyclic aromatic hydrocarbons (PAHs) and organic halogens as well.

Mottier and Boller (1996), working in Zurich, measured metal concentrations in road runoff and found average values of $300 \mu \mathrm{g} / \mathrm{L}$ for lead, $4 \mu \mathrm{g} / \mathrm{L}$ for cadmium, $150 \mu \mathrm{g} / \mathrm{L}$ for copper and $500 \mu \mathrm{g} / \mathrm{L}$ for zinc. Information on pavement material type was not included. Averaged roof runoff concentrations (from tile 
and polyester roofs) were also measured at $16 \mu \mathrm{g} / \mathrm{L}$ for lead, $0.17 \mu \mathrm{g} / \mathrm{L}$ for cadmium, $225 \mu \mathrm{g} / \mathrm{L}$ for copper and $42 \mu \mathrm{g} / \mathrm{L}$ for zinc. Boller concluded that copper installations on buildings seem to represent the largest source for the emission of this metal into the environment. Stark, et al. (1995) arrived at a similar conclusion, estimating that stormwater from roofs may be responsible for more the $60 \%$ of the copper in Austria's combined sewers.

Researchers in Marquette, Michigan, collecting wet weather flow concurrently at 33 sites during twelve storms detected discernable differences in runoff quality between a variety of impervious source areas. Commercial and residential rooftops were found to produce the lowest concentration of suspended solids, but the highest concentration of dissolved metals such as lead, zinc, cadmium, and copper. Parking lots produced the highest concentrations for all PAH compounds and high concentrations of zinc, total cadmium and total copper. Low traffic streets were also identified as a major producer of total cadmium (Steuer, et al. 1997).

Jurgen Forster (1996) sampled and analyzed roof runoff for heavy metals (Cd, Cu, Zn, Pb) between April 1993 and May 1994. Measurement were made with an experimental roof system situated on the campus of the University of Bayreuth and at various locations in the urban area of Bayreuth, Northern Bavaria. The experimental roof systems allowed the influence of different roof materials (concrete tiles, zinc sheet, pantiles, fibrous cement) on runoff quality to be compared. Large differences in runoff pollutant concentrations from various roofs were interpreted to indicate that the pollutants were not only being transported to the surface via the atmosphere, but also originating from the material itself. Extremely high values of zinc and copper were measured when the roof system, or parts of it, were made of metal panels, flashing and gutters. For example, runoff concentrations from zinc sheet roofing started almost three orders of magnitude higher and remained more than twenty times above the values measured for the roofs affected only by atmospheric deposition. Forster noted that the most critical effect of runoff pollution containing heavy metals is their high ecotoxicity in receiving waters. Mean runoff concentrations values at his study sites exceeded by about two orders of magnitude local toxicity thresholds. Peak values exceeded thresholds by a factor of 1000 or more. Forster concluded by advocating abandoning the use of exposed metal surfaces on roofs and walls of buildings.

Good (1993) reported the results of one time sampling of runoff from a rusty galvanized metal roof, a weathered metal roof, a built-up roof of plywood covered with roofing paper and tar, a flat tar-covered roof which had been painted with a fibrous reflective aluminum paint, and a relatively new anodized aluminum material at a sawmill facility on the coast of Washington. The research was carried out following the discovery that stormwater samples from 
the site were acutely toxic and contained high concentrations of zinc. Differences in contributions of copper, lead, and zinc were noticed between each roof type. Built-up roofing contributed the highest concentrations of dissolved copper $(128 \mu \mathrm{g} / \mathrm{L})$ and total copper $(166 \mu \mathrm{g} / \mathrm{L})$, approximately 10 times higher than levels detected in runoff from the other roofs sampled. Runoff from the rusty galvanized metal roof contained the highest concentrations of dissolved lead $(35 \mu \mathrm{g} / \mathrm{L})$ and total lead $(302 \mu \mathrm{g} / \mathrm{L})$, dissolved zinc $(11,900 \mu \mathrm{g} /$ $\mathrm{L})$ and total zinc $(12,200 \mu \mathrm{g} / \mathrm{L})$. High concentrations of zinc were noted in runoff from each type of roof sampled at the site. Dissolved metals concentrations and toxicity remained high in roof runoff samples collected three hours after the beginning of the storm event, indicating metals leaching continued throughout storm events. All roof runoff samples were found to be highly toxic to rainbow trout, with the aluminum painted roof least toxic. Roof runoff sample concentrations exceeded the water quality criteria for copper, lead, and zinc in all samples, though the greatest exceedences were for zinc. Acid rain and the high ionic content of the coastal atmosphere were thought to have contributed to the rapid corrosion of the galvanized metal roofs and leaching of zinc. Interestingly, plastic rain gutters were reported to be a source of lead.

The corrosion of galvanized roofs in a coastal environment is a source of heavy metal pollution. The zinc content of roof runoff during rainfall events in Malaysia showed continued elevated zinc levels in roof runoff after the first flush, indicating that zinc was leaching from the galvanized roof surface during the storm.

Thomas and Greene (1993) working in and near Armidale, Australia, found differences in metal contaminate levels between urban and rural roofs associated with variations in atmospheric deposition and differences related to antecedent dry periods. He also found runoff water quality influenced by different roof types. Zinc concentrations were significantly higher in galvanized iron roof catchments, while $\mathrm{pH}$, conductivity and turbidity levels were higher in concrete tile roof catchments.

Pitt et al. (1995) found high concentrations of organic constituents in runoff from several types of paved source areas. Paved areas receive pollutant contributions from vehicle exhaust emissions, tire and brake wear, vehicle corrosion and leaks, carry-in and atmospheric deposition, which are then washed off to varying degrees in subsequent rains. However, differences noted between sampling sites indicate potential differences in contribution of organics from paving materials themselves. Polycyclic aromatic hydrocarbons (PAHs), in particular, are of concern, because they are known to have potential for adverse effects on a large number of invertebrates, fishes, birds, and mammals (Kennish, 1992). Chlorination of PAHs in water treatment plants have also been found to produce carcinogenic by-products (Kopfler, et al. 1977). 


\subsubsection{Exposed Wooden Material/Treated Wood}

The literature also supports the concern of toxicant leaching potential associated with a variety of woods, especially treated woods, used for utility poles, recreational and other wooden structures. Typical treated woods include chromated-copper-arsenate (CCA), ammoniacal copper zinc arsenate (ACZA), pentachlorophenol (PCP), and creosote. The volume of treated wood produced in the United States in 1987 was as follows: CCA/ACZA - 11.9 million cubic meters, PCP - 1.4 million cubic meters, Creosote -2.8 million cubic meters (Micklewright, 1989).

Both arsenic and chromium are heavy metals which have acute environmental health risks associated with them. Copper does not generally constitute a human health risk, however low concentrations of copper, in certain ionic forms, are highly toxic to marine fauna and flora. The known toxicity of arsenic and chromium to humans has resulted in concern about the possible introduction into the environment of large amounts of these metals in treated wood products (Brooks 1993).

Pentachlorophenol is a highly chlorinated, synthetic preservative containing pentachlorophenol, 2,3,4,6-tetrachlorophenol, higher chlorophenols, dioxins and furans (Shields et al., 1976). Arsenault (1975) and Stranks (1976) reported the presence of pentachlorophenol around the base, and in drainage ditches near treated utility poles. Stranks reported drainage ditch waters with 1.8 times the 96-h LC50 of chlorophenol for salmonids near PCP treated utility poles. In 1991, the U.S. EPA determined that the use of pentachlorophenol poses the risk of oncogenicity because of the presence of hexachlorodibenzop-dioxin and hexacholorobenzene, both of which have the potential to produce teratogenic/fetotoxic effects) (CALEPA 1996).

Creosote is a rather complex chemical that is comprised of more than 160 different distillates that occur in coal-tar, including aromatic hydrocarbons (such as naphthalene, anthracene, benzene, toluene, xylene, acenaphthene, phenanthrene, and fluorene), tar acids (such as phenols, cresols, xylenols, and naphthols), and tar bases (including pyridines, guinolines, and acridines) many of which are toxicants and carcinogens (Shields 1976). The U.S. EPA determined that creosote has the potential for oncogenicity and mutagenicity (CALEPA 1996).

The following section describes a preliminary set of experiments conducted at $\mathrm{UAB}$ to investigate the potential of leaching of some of the different materials that can be used in construction. 


\subsection{Leaching of Various Construction Materials}

Some construction material leaching tests were conducted by Pitt et al. (2000) as part of a stormwater treatability research project. This project included the construction of pilot-scale treatment devices and there was concern about the selection of the construction materials that could affect the test results. Therefore, before the pilot-scale devices were constructed, as series of tests were conducted to examine the pollutant leachability of different potential construction materials. Samples of the various materials were left to soak in deionized water for set periods of time, and then the water was analyzed for a broad list of constituents of interest.

Table 1.5 lists potential contaminants from some materials that may be used in bench-scale and pilot-scale test equipment (Cowgill, 1988). Cowgill found that extensive steam cleaning (at least five washings using steam produced from distilled water) practically eliminated all contamination problems from sampling equipment. Cemented materials should probably be avoided, as is evident from this table. Threaded or bolted together components are much preferable.

Table 1.5 Potential sample contamination from sampler material (Cowgill 1988).

\begin{tabular}{|c|c|}
\hline Material: & Contaminant: \\
\hline PVC - threaded joints & chloroform \\
\hline PVC - cemented joints & $\begin{array}{l}\text { methylethyl ketone, toluene, acetone, methylene chloride, } \\
\text { benzene, ethyl acetate, tetrahydrofuran, cyclohexanone, } \\
\text { organic tin compounds, and vinyl chloride }\end{array}$ \\
\hline Teflon ${ }^{\mathrm{M} M}$ & nothing \\
\hline polypropylene and polyethylene & plasticizers and phthalates \\
\hline $\begin{array}{l}\text { fiberglass reinforced epoxy } \\
\text { material (FRE) }\end{array}$ & nothing \\
\hline stainless steel & chromium, iron, nickel, and molybdenum \\
\hline glass & boron and silica \\
\hline
\end{tabular}

Pitt et al. (2000) tested the leaching potentials for many materials that may be used in bench-scale and pilot-scale treatment units, and some of these materials are likely exposed to stormwater during typical construction applications. Samples of each material were immersed for a period of $72 \mathrm{~h}$ in approximately $500 \mathrm{~mL}$ of laboratory grade $18 \mathrm{megohm}$ water. A sample blank was also prepared. Analyses conducted on each of these samples, and the sample blank, were the same as performed on the pilot-scale treatment devices. Tables 1.6 and 1.7 present the contaminants that were found in the leaching water at the end of the test in high concentrations that may affect the test results. The most serious problems occur with plywood, including both treated and untreated wood. Attempting to seal the wood with Formica and caulking was 
Table 1.6 Potential sample contamination from construction materials (Pitt et al. 2000).

\begin{tabular}{|c|c|}
\hline Material: & Contaminant observed: \\
\hline untreated plywood & $\begin{array}{l}\text { toxicity, chloride, sulfate, sodium, potassium, calcium, } 2,4- \\
\text { dimethylphenol, benzylbutyl phthalate, bis(2-ethylhexyl) } \\
\text { phthalate, phenol, N-nitro-so-di-n-propylamine, 4-chloro-3- } \\
\text { methylphenol, 2,4-dinitrotoluene, 4-nitrophenol, alpha BHC, } \\
\text { gamma BHC, 4,4'-DDE, endosulfan II, methoxychlor, and endrin } \\
\text { ketone }\end{array}$ \\
\hline treated plywood (CCA) & $\begin{array}{l}\text { toxicity, chloride, sulfate, sodium, potassium, hexachloroethane, } \\
\text { 2,4-dimethylphenol, bis( } 2 \text {-chloroethoxyl) methane, 2,4- } \\
\text { dichlorophenol, benzylbutyl phthalate, bis(2-ethylhexyl) phthalate, } \\
\text { phenol, 4-chloro-3-methylphenol, acenaphthene, 2,4- } \\
\text { dinitrotoluene, 4-nitrophenol, alpha BHC, gamma BHC, beta } \\
\text { BHC, 4,4'-DDE, 4,4'-DDD, endosulfan II, endosulfan sulfate, } \\
\text { methoxychlor, endrin ketone, and copper (likely), chromium } \\
\text { (likely), arsenic (likely) }\end{array}$ \\
\hline treated plywood (CCA) & toxicity, chloride, sulfate, sodium, potassium, bis(2-chloroethyl) \\
\hline and Formica & $\begin{array}{l}\text { ether*, diethylphthalate, phenanthrene, anthracene, benzylbutyl } \\
\text { phthalate, bis(2-ethylhexyl) phthalate, phenol*, N-nitro-so-di-n- } \\
\text { propylamine, 4-chloro-3-methylphenol }{ }^{*}, 4 \text {-nitrophenol, } \\
\text { pentachlorophenol, alpha BHC, } 4,4^{\prime} \text {-DDE, endosulfan II, } \\
\text { methoxychlor, endrin ketone, and copper (likely), chromium } \\
\text { (likely), arsenic (likely) }\end{array}$ \\
\hline treated plywood (CCA), & lowered $\mathrm{pH}$, toxicity, bis(2-chloroethyl) ether*, \\
\hline Formica and silica caulk & $\begin{array}{l}\text { hexachlorocyclopentadiene, diethylphthalate, bis(2-ethylhexyl) } \\
\text { phthalate, phenol*, N-nitro-so-di-n-propylamine, 4-chloro-3- } \\
\text { methylphenol*, alpha BHC, heptachlor epoxide, 4,4'-DDE, } \\
\text { endosulfan II, and copper (likely), chromium (likely), arsenic } \\
\text { (likely) }\end{array}$ \\
\hline Formica and silica caulk & $\begin{array}{l}\text { lowered pH, toxicity, 4-chloro-3-methylphenol, aldrin, and } \\
\text { endosulfan } 1\end{array}$ \\
\hline silica caulk & lowered $\mathrm{pH}$, toxicity, and heptachlor epoxide \\
\hline PVC pipe & N-nitrosodiphenylamine, and 2,4-dinitrotoluene \\
\hline $\begin{array}{l}\text { PVC pipe with cemented } \\
\text { joint }\end{array}$ & bis(2-ethylhexyl) phthalate*, acenaphthene, and endosulfan sulfate \\
\hline plexiglass and plexiglass & naphthalene, benzylbutyl phthalate, and bis(2-ethylhexyl) \\
\hline cement & phthalate, and endosulfan II \\
\hline aluminum & toxicity, and aluminum (likely) \\
\hline plastic aeration balls & 2,6-dinitrotoluene \\
\hline filter fabric material & $\begin{array}{l}\text { acenaphthylene, diethylphthalate, benzylbutyl phthalate, bis(2- } \\
\text { ethylhexyl) phthalate, and pentachlorophenol }\end{array}$ \\
\hline sorbent pillows & diethylphthalate, and bis(2-ethylhexyl) phthalate \\
\hline black plastic fittings & pentachlorophenol \\
\hline reinforced PVC tubing & diethylphthalate, and benzylbutyl phthalate \\
\hline fiberglass window & toxicity, dimethylphthalate, diethylphthalate*, bis(2-ethylhexyl) \\
\hline screening & $\begin{array}{l}\text { phthalate, di-n-octyl phthalate, phenol, 4-nitrophenol, } \\
\text { pentachlorophenol, and 4,4'-DDD }\end{array}$ \\
\hline Delrin ${ }^{\mathrm{TM}}$ & benzylbutyl phthalate \\
\hline Teflon ${ }^{\mathrm{M}} \mathrm{A}$ & nothing (likely) \\
\hline glass & zinc (likely) \\
\hline
\end{tabular}

note: * signifies that the observed concentrations in the leaching solution were very large compared to the other materials. 
partially successful, but toxicants were still leached. Covering of the Formica clad plywood with polyethylene plastic sheeting was finally used to eliminate any potential problem, for example. Fiberglass screening material, especially before cleaning, also causes a potential problem with plasticizers and other organics. PVC and aluminum may be acceptable materials, if phthalate esters and aluminum contamination can be tolerated. The most serious concern is associated with the use of galvanized metals, as expected, where the tests indicated extremely high zinc concentrations, or the exposure of treated woods to stormwater (its typical application).

Table 1.7 Analyses of washoff from various construction materials.

\begin{tabular}{|c|c|c|c|c|c|c|c|c|}
\hline Sample & $\begin{array}{c}\mathrm{Cu} \\
(\mu \mathrm{g} / \mathrm{L})\end{array}$ & $\begin{array}{c}\mathrm{Cd} \\
(\mu \mathrm{g} / \mathrm{L})\end{array}$ & $\begin{array}{c}\mathrm{Pb} \\
(\mu \mathrm{g} / \mathrm{L})\end{array}$ & $\begin{array}{c}\mathrm{Zn} \\
(\mu \mathrm{g} / \mathrm{L})\end{array}$ & $\begin{array}{c}\mathrm{Fe} \\
(\mu \mathrm{g} / \mathrm{L})\end{array}$ & $\begin{array}{c}\mathrm{Cr} \\
(\mu \mathrm{g} / \mathrm{L}) \\
\end{array}$ & $\begin{array}{c}\mathrm{Mg} \\
(\mu \mathrm{g} / \mathrm{L}) \\
\end{array}$ & $\begin{array}{c}\mathrm{Ca} \\
(\mu \mathrm{g} / \mathrm{L}) \\
\end{array}$ \\
\hline silica caulk & 29 & $<\operatorname{lod}^{1}$ & $<\operatorname{lod}$ & 14 & 48 & 8 & $<\operatorname{lod}$ & 0.08 \\
\hline $\begin{array}{r}\text { formica } \\
\text { and silica } \\
\text { caulk }\end{array}$ & 54 & $<\operatorname{lod}$ & $<\operatorname{lod}$ & 26 & 110 & 8 & $<\operatorname{lod}$ & 0.38 \\
\hline $\begin{array}{l}\text { metal roof } \\
\text { runoff }\end{array}$ & 41 & $<\operatorname{lod}$ & 32 & 10,200 & 440 & 11 & 0.13 & 1.2 \\
\hline $\begin{array}{r}\text { treated } \\
\text { plywood }\end{array}$ & 1,300 & $<$ lod & 33 & 93 & 110 & 2,800 & 0.02 & 0.67 \\
\hline $\begin{array}{l}\text { untreated } \\
\text { plywood }\end{array}$ & 79 & $<\operatorname{lod}$ & $<\operatorname{lod}$ & 67 & 310 & 12 & 1.3 & 3.2 \\
\hline $\begin{array}{r}\text { washed } \\
\text { PVC and } \\
\text { PVC } \\
\text { cement }\end{array}$ & 36 & $<\operatorname{lod}$ & $<\operatorname{lod}$ & 32 & 83 & 8 & $<\operatorname{lod}$ & 0.60 \\
\hline $\begin{array}{r}\text { washed } \\
\text { geotextile } \\
\text { filter fabric }\end{array}$ & 44 & $<\operatorname{lod}$ & $<\operatorname{lod}$ & 32 & 110 & 16 & 0.05 & 1.2 \\
\hline $\begin{array}{r}\text { washed } \\
\text { fiberglass } \\
\text { window } \\
\text { screen }\end{array}$ & 32 & 17 & $<\operatorname{lod}$ & 88 & 47 & 8 & $<$ lod & 0.10 \\
\hline
\end{tabular}

${ }^{1}<$ lod: less than the limit of detection.

Table 1.8 summarizes the selected materials used in the construction of the test apparatus. These tables indicate that care must be taken when selecting test equipment. The use of Teflon ${ }^{\mathrm{TM}}$ reduces most of the problems, but it is quite expensive. Delrin ${ }^{\mathrm{TM}}$ is almost as effective, is somewhat less expensive, and is much easier to machine when manufacturing custom equipment. Both of these materials are fragile and cannot withstand rough handling. Glass is not usable for most large treatability test equipment, but is commonly used in bench-scale tests. 
Table 1.8 Preliminary construction material leach test (Pitt et al. 2000).

\begin{tabular}{ll}
\multicolumn{1}{c}{ Material } & \multicolumn{1}{c}{ Leach Potential } \\
\hline $\begin{array}{l}\text { PVC pipe and cement } \\
\text { polyethylene sheeting }\end{array}$ & $\begin{array}{l}\text { LOW } \\
\text { LOW (n-nitroso-di-n-propylamine) }\end{array}$ \\
Plexiglas $^{\text {TM }}$ and cement & LOW (conductivity, chloride, sodium) \\
Formica $^{\mathrm{TM}}$ and caulk & $\begin{array}{l}\text { LOW (toxicity, conductivity, pH, nitrobenzene, 4-chloro-3- } \\
\text { methylphenol) }\end{array}$ \\
$\begin{array}{l}\text { aluminum angle bracket } \\
\text { Amoco 4557 filter fabric }\end{array}$ & $\begin{array}{l}\text { LOW (toxicity, conductivity, chloride, calcium, pentachlorophenol) } \\
\text { Lunderboom (toxicity, conductivity, sulfate, pentachlorophenol) }\end{array}$ \\
plastic screen & $\begin{array}{l}\text { HIGH (toxicity) } \\
\text { LOW (phenol, 4-nitrophenol, pentachlorophenol, di-n- } \\
\text { octylphthalate) } \\
\text { HIGH (toxicity, hexachloroethane, 2,4-dimethylphenol, 4-chloro-3- } \\
\text { methylphenol, 4-nitrophenol; likely heavy metals) }\end{array}$ \\
\hline
\end{tabular}

\subsection{Conclusions}

This chapter presented information showing the potential benefits of using alternative building materials as a stormwater management control. As an example, although roof runoff may only contribute about 10 to $20 \%$ of all stormwater runoff from typical residential areas, almost all of the zinc has been found to originate from this source due to the use of galvanized metal roof flashing and drainage gutters and downspouts. Serious problems may also be associated with the use of other metals on buildings, especially copper. Pavement contributes large fractions of the total stormwater runoff volume in most areas, and the selection of different pavement materials may have significant effects on runoff quality, although there is currently very little supportive data. The use of other building materials, especially treated wood, may also have significant adverse effects on runoff quality. It is likely that careful selection of building materials may help reduce stormwater pollutant concentrations, although additional research is needed to quantify the likely benefits and to test different materials and associated pollutant release and fate processes. 


\section{References}

Arsenault, R.D., 1975. Pentachlorophenol and Contained Chlorinated Diabenzodioxins in the Environment. Proceedings of the American Wood Preservers Association.

Bannerman, R., D.W. Owens, R.B. Dodds, and N.J. Hornewer. 1997. "Sources of pollutants in Wisconsin stormwater." Water Science and Technology. Vol. 28, No. 3-5, pp. 241-259.

Boller, M. 1993. Tracking Heavy Metals Reveals Sustainability Deficits of Urban Drainage Systems, Water Science \& Technology. 35(9): 77-87.

Brooks, Kenneth M., $\mathrm{PhD}$, Literature Review and Assessment of the Environmental Risks Associated with the Use of CCA and ACZA Treated Wood Products in Aquatic Environments, prepared for Western Wood Preservers Institute, Vancouver, WA.

CALEPA, 1996. California Environmental Protection Agency, Draft Concept Paper, Task C.1.

Clark, S. and R. Pitt. 1999. Stormwater Treatment at Critical Areas: Evaluation of Filtration Media. U.S. Environmental Protection Agency, Cooperative Agreement No. CX 824933, Water Supply and Water Resources Division, U.S. Environmental Protection Agency, Cincinnati, Ohio.

Cowgill, U.M. 1988. "Sampling waters, the impact of sample variability on planning and confidence levels." In: Principles of Environmental Sampling. Edited by L.H. Keith. ACS Professional Reference Book. American Chemical Soc. pp. 171-189. EPA 1983. (U.S. Environmental Protection Agency). Results of the Nationwide Urban Runoff Program. Water Planning Division, PB 84-185552, Washington, D.C., December 1983.

Field, R., and R. Turkeltaub. 1981. "Urban runoff receiving water impacts: program overview." Journal of Environmental Engineering, 107:83-100.

Field, R., E.J. Struzeski, Jr., H.E. Masters and A.N. Tafuri. 1973. Water Pollution and Associated Effects from Street Salting. EPA-R2-73-257, U.S. Environmental Protection Agency, Cincinnati, Ohio. May 1973.

Fram, S., M.K. Stenstrom, and G. Silverman. 1993. "Hydrocarbons in urban runoff." Journal of Environmental Engineering, 113:1032-1046.

Forster, Jurgen, 1984. Heavy Metal and Ion Pollution Patterns in Roof Runoff, Proceeding of the Seventh International Conference on Urban Storm Drainage, Hannover, Germany

Good, James C., 1987. Roof Runoff as a Diffuse source of metals and Aquatic Toxicity in Stormwater, Water Science Technology. Vol28, No.3-5, pp317-321.

Hoffman, E.J., G.L. Mills, J.S. Latimer, and J.G. Quinn. 1996. "Urban runoff as a source of polycyclic aromatic hydrocarbons to coastal waters." Environment Science and Technology, 18:580-587.

Kennish, M.J. 1992. Ecology of Estuarines:Anthropogenic Effects. CRC, Boca Raton, FL. USA

Koeppe,D.E., 1977. comp. Vol. IV: “Soil-Water-Air-Plant Studies.”In: Environmental Contamination by Lead and Other Heavy Metals, G. L. Rolfe and K. A. Peinbold, 
eds. Institute for Environmental Studies, Univ. of Illinois, Urbana-Champaign, Illinois. July 1977.

Kopfler, F. C., R.G. Melton, J.L. Mullaney, and R. G. Tardiff. 1977. Human Exposure to Water Pollutants. In: Fate of Pollutants in the Air and Water Environments Part 2, I.H. Suffet, ed. John Wiley \& Sons. pp 419-434.

Mottier and Boller, 1996 Quantitative and Qualitative Aspekte des Dachwassers, Proceedings Engelberg Courses, VSA, Strassbugstrasse 10, CH-8026 Zurich

Phillips, G. R., and R. C. Russo. 1978. Metal Bioaccumulation in Fishes and Aquatic Invertebrates: A Literature Review, EPA-600/3-78-103, U.S. Environmental Protection Agency, Duluth, Minnesota.

Pitt, R. 1987. Small Storm Urban Flow and Particulate Washoff Contributions to Outfall Discharges, Ph.D. Dissertation, Civil and Environmental Engineering Department, University of Wisconsin, Madison, WI, November 1987.

Pitt, R. 1995. Biological effects of urban runoff discharges Stormwater Runoff and Receiving Systems - Impact Monitoring and Assessment, E.E. Herricks ed. Proceedings of ASCE Engineering Foundation Conference, Crested Butte, Colorado, CRC Lewis, New York, NY, 127-162.

Pitt, R., R. Field, M. Lalor, and M. Brown. 1995. Urban stormwater toxic pollutants: assessment, sources and treatability., Water Environment Research. Vol. 67, No. 3, pp. 260-275. May/June 1995.

Pitt, R.E. 1997. "Unique Features of the Source Loading and Management Model (SLAMM)." Journal of Water Management Modeling R200-02. doi: 10.14796/JWMM.R200-02.

Pitt, R.E. 1998. "Small Storm Hydrology and Why it is Important for the Design of Stormwater Control Practices." Journal of Water Management Modeling R204-04. doi: 10.14796/JWMM.R204-04.

Pitt, R. and P. Bissonnette. 1984. Bellevue urban runoff program, summary report. PB84 237213, Water Planning Division, U.S. Environmental Protection Agency and the Storm and Surface Water Utility, Bellevue, Washington.

Pitt, R. and M. Bozeman. 1982. Sources of Urban Runoff Pollution and Its Effects on an Urban Creek, EPA-600/52-82-090, U.S. Environmental Protection Agency, Cincinnati, Ohio, December 1982.

Pitt, R.E. and J. Lantrip. 1999. "Infiltration Through Disturbed Urban Soils." Journal of Water Management Modeling R206-01. doi: 10.14796/JWMM.R206-01.

Pitt, R. and J. Voorhees. 1996. "Critical Source Area Controls in the SLAMM Water Quality Model." A National Symposium: Assessing the Cumulative Impacts of Watershed Developments on Aquatic Ecosystems and Water Quality. U.S. EPA and Northeastern Illinois Planning Commission. Chicago, Illinois, March 1996.

Pitt, R., M. Lilburn, S. Nix, S.R. Durrans, S. Burian, J. Voorhees, and J. Martinson. 2000. Guidance Manual for Integrated Wet Weather Flow (WWF) Collection and Treatment Systems for Newly Urbanized Areas (New WWF Systems). U.S. Environmental Protection Agency. 612 pgs. 
Rubin, A.J., 1976. (editor). Aqueous-Environmental Chemistry of Metals. Ann Arbor Science Publishers, Ann Arbor, Michigan.

Shaheen, D.G. 1976. Contributions of Urban Roadway Usage to Water Pollution. 600/ 2-75-004. U.S. Environmental Protection Agency. Washington, D.C.

Shields, J.K., and D.W. Stranks, 1975. Wood Preservatives and the Environment, Eastern forest Products Laboratory Report, April. pages 128-144.

Solomon, R.L., and D.F.S. Natusch. 1977. Vol:III: "Distribution and Characterization of Urban Dists." In: Environmental Contamination by Lead and Other Heavy Metals, G. L. Rolfe and K. G. Reinbold, eds. Institute for Environmental Studies, Univ. of Illinois, Urbana-Champaign, Illinois. July 1977.

Stark, W., R. Kernbeis, H. Raeissi, H.P. Brunner, 1995, Wo liegen die Grenzen der Schadstoffentfrachtung des Klarschlannes? 1. Teil:Schwermetalle, Report TU Viewnna, Institute for Water Quality and Refuse Management, Vienna.

Steuer, Jeffrey, William Selbig, Nacy Hornewer, and Jeffrey Prey. 1997. Sources of Contamination in an Urban Basin in Marquette, Michigan and an Analysis of Concentrations, Loads, and Data Quality, U.S. Geological Survey Water-Resources Investigations Report 97-4242. Middleton, Wisconsin.

Stranks, D.W., 1976. Wood Preservatives: Their Depletion as Fungicides and Fate in the Environment. Canadian Forest Service Technical Report 10.

Thomas, P.R. and G.R. Greene. 1993. Rainwater Quality from Different Roof Catchments, Water Science Tech. Vol. 28, No. 3-5, pp.291-299.

Verschueren, K. 1983. Handbook of Environmental Data on Organic Chemicals, 2nd edition. Van Nostrand Reinhold Co., New York.

Wilber, W. G., and J. V. Hunter. 1980. The Influence of Urbanization on the Transport of Heavy Metals in New Jersey Streams, Water Resources Research Institute, Rutgers University, New Brunswick, New Jersey. 